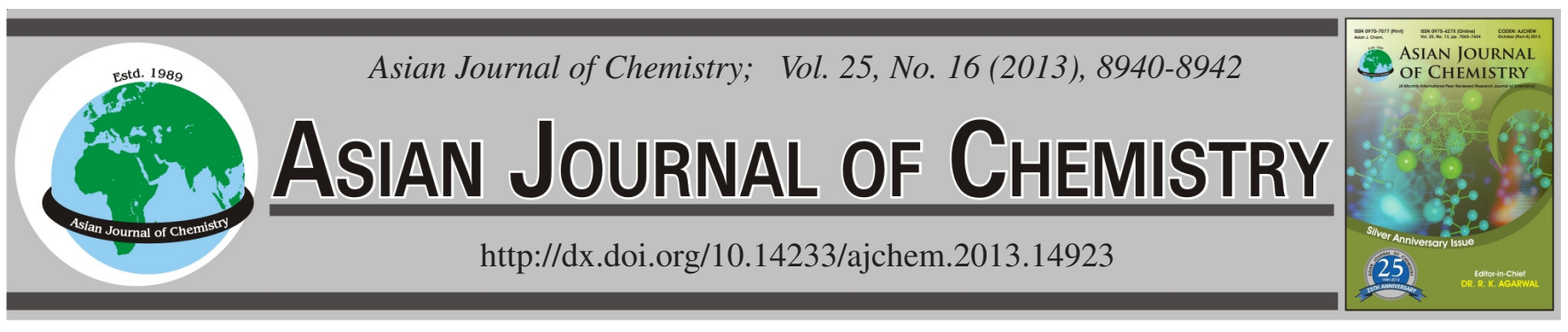

\title{
Determination of Catechin by High Performance Liquid Chromatography and Ultraviolet Spectrophotometer
}

\author{
QING HuO ${ }^{1, *}$, JiNG HAO $^{1}$ and RONGJIAN SHI ${ }^{2}$
}

${ }^{1}$ Biochemical Engineering College of Beijing Union University, Beijing 100023, P.R. China ${ }^{2}$ Institute of High Energy Physics, Chinese Academy of Sciences,Beijing 100049, P.R. China

*Corresponding author: Tel: +86 10 52072259; E-mail: huo_q2002@yahoo.com.cn

(Received: 5 December 2012;

Accepted: 9 September 2013)

AJC-14085

\begin{abstract}
Catechin exist widely in plants, which can be used as medicine and treated for cardiovascular disease, cancer and other features. This experiment established a quantitative method for the determination of catechin, so as to provide references for its development and utilization. The contents of catechin was determined by HPLC. The HPLC conditions were as follows: A Diamonsil $\mathrm{C}_{18}$ column as separation column $(250 \mathrm{~mm} \times 4.6 \mathrm{~mm}$ i.d., $10 \mu \mathrm{m})$, mobile phase of methanol-water-acetic acid $(\mathrm{V}: \mathrm{V}: \mathrm{V}=15: 84: 1)$, flow rate of $0.9 \mathrm{~mL} / \mathrm{min}$, detection wavelength of $278 \mathrm{~nm}$ and column temperature of $30^{\circ} \mathrm{C}$, HPLC standard curve: $\mathrm{y}=555111 \mathrm{x}+248469$, $\mathrm{R}^{2}=0.9982$, the linear relationship between catechin concentration and peak area was good in the range of 3.24-6.43 $\mu \mathrm{g}$, the recovery rates of the catechin was $100.33 \%$ with RSD of $1.44 \%$. The contents of catechin were determined by UV spectrophotometer and UV conditions were as follows: Ethanol as a constant volume solvent, the absorbance of catechin was measured at $278 \mathrm{~nm}$. Determination of catechin standard curve was $\mathrm{y}=0.05 \mathrm{x}, \mathrm{R}^{2}=1$, linear range was $0.05-0.4 \mathrm{mg} / \mathrm{mL}$.
\end{abstract}

Key Words: Catechin, HPLC, UV.

\section{INTRODUCTION}

The chemical name of catechin is polyhydroxy flavan-3phenol (m.f. $\mathrm{C}_{15} \mathrm{H}_{14} \mathrm{O}_{6} \cdot \mathrm{H}_{2} \mathrm{O}$, m.w. 308.28). Catechin distributes widely in plants, catechin can be obtained from the system of water/acetic acid solution, get the acicular crystals containing water of crystallization, m.p. $93-96^{\circ} \mathrm{C}$, optical rotation $+16^{\circ}-$ $+18.4^{\circ}$. Racemates are also shown as acicular crystals, m.p. 212 to $216^{\circ} \mathrm{C}$. Slightly soluble in cold water, ether, soluble in hot water, ethanol, acetic acid and acetone, insoluble in benzene, chloroform and petroleum ether. When catechin meet the light, it is easy to degenerate, so it needs a cool, dry, dark environment kept under seal ${ }^{1}$.<smiles>[R]c1cc(C2Oc3cc(O)cc(O)c3CC2O)cc(O)c1O</smiles>

Catechin is one of the polyphenol. Because of the bitter taste, so catechin has a great influence on the taste of the tea.
Catechin can be divided into three free patterns (Catechin, $\mathrm{C}$; Epicatechin, EC and Epigallocatechin, EGC) and two esterified gallic acid (Epicatechin gallate, ECG and Epigallocatechin gallate, EGCG), the contents of ECG and EGCG are more ${ }^{2,3}$. Variety of catechins are separated and purified from tea and widely used in the food and drug.

Catechin is a natural anti-oxidant, antioxidant activity is higher than vitamin E. It can remove the free radicals produced by the body to protect cell membranes. Catechin is a flavonoid polyphenol. The main dietary sources of catechin are from tea, apples, grapes, red wine and cocoa. Green tea contains a high concentration of catechins ${ }^{4-6}$. Scavenging free radicals function, so it can slow down the senile. Clinical experiments show that catechins can obviously reduce plaque and the alleviation of periodontal disease.

\section{EXPERIMENTAL}

Acetic acid, ethanol (AR), methanol (chromatographic class); phosphomolybdic acid, sodium carbonate (CP, Beijing Chemical Reagent Company); catechin reference substance, content $\geq 99 \%$ (lot number:UE060080, Beijing Tianbao materialized Biotechnology Co. Ltd.); catechin, content $\geq 95 \%$ (the Shanxi Sciphar biological technology Co. Ltd.); distilled, deionized water (homemade). 
UV 1800 ultraviolet spectrophotometer, Beijing Puxi General Corporation; HPLC analysis is performed using a waters liquid chromatographic systems (Waters company, USA) HPLC system, A diamonsil $\mathrm{C}_{18}$ column $(250 \mathrm{~mm} \times 4.6$ $\mathrm{mm}$ i.d., $10 \mu \mathrm{m}$ ) is employed for the separation of samples. All solutions are filtered through $0.22 \mu \mathrm{m}$ membranes (Chromatography Science and Technology Co., Tianjin, China) before HPLC analysis; KQ-50DB ultrasonic cleaner; microinjector; analytical balance; volumetric flask; cuvette.

Chromatography conditions: $\mathrm{A}$ diamonsil $\mathrm{C}_{18}$ column $(250 \mathrm{~mm} \times 4.6 \mathrm{~mm}$ i.d., $10 \mu \mathrm{m})$, mobile phase of methanol water - acetic acid $(\mathrm{V}: \mathrm{V}: \mathrm{V}=15: 84: 1)$, flow rate of $0.9 \mathrm{~mL} /$ min, detection wavelength of $278 \mathrm{~nm}$ and $30{ }^{\circ} \mathrm{C}$ as column temperature, sample amount of $10 \mu \mathrm{L}$, retention time of 22 min theoretical plate number is 6000 .

Preparation of catechin solution: $3.20 \mathrm{mg}$ catechin reference substance with constant weight is weighed precisely and put into $10 \mathrm{~mL}$ volumetric flask, then dissolved in a solution and diluted to $10 \mathrm{~mL}$.

Methodology investigation: Investigation of linear relationship. 10, 12.5, 15, 17.5, $20 \mu \mathrm{L}$ mixed solution of catechin reference substance are measured respectively and injected by the conditions in 2.3.1.1. Sample amount as abscissa (x), peak area as ordinate (y), the line relationship of the catechin reference substance is investigated; Precision test. The same control solution is injected for 5 times continuously, RSD of catechin peak areas is calculated; Stability test. The control solution is injected at $0,1,2,3,4 \mathrm{~h}$ respectively, the peak areas of catechin and RSD are figured out; Recovery test. High, medium and low concentration groups are set, 3 shares of each group. The ratios of added control substance and tested substance in high, medium and low concentration groups are set as 1.2:1, $1: 1$ and $0.8: 1$. The average recovery rate and RSD are calculated.

Ultraviolet spectrophotometer: A small amount of catechin reference substance with constant weight is weighed precisely and put into $100 \mathrm{~mL}$ volumetric flask, then dissolved in a reference solution (ethanol, methanol + water or phosphorus molybdate ${ }^{7}$ ) and diluted to $100 \mathrm{~mL}$. Shake well, put it aside. Exact amount taken from the solution 1, 2, 3, 4, 5, 6, 8, $10 \mathrm{~mL}$ solution placed in $25 \mathrm{~mL}$ volumetric flasks respectively and diluted to $25 \mathrm{~mL}$ with reference solution. By wavelength scanning of catechin solution, determine catechin positions of absorption peak and make a standard curve at the peak position.

\section{RESULTS AND DISCUSSION}

\section{Results of methodology investigation in HPLC}

Investigation of linear relationship: As shown in Fig. 1, the result indicated catechin had good linear relationship with peak area in the range of 3.24-6.43 $\mu \mathrm{g}$, the regression equation is $\mathrm{y}=555111 \mathrm{x}+248469, \mathrm{R}^{2}=0.9982$.

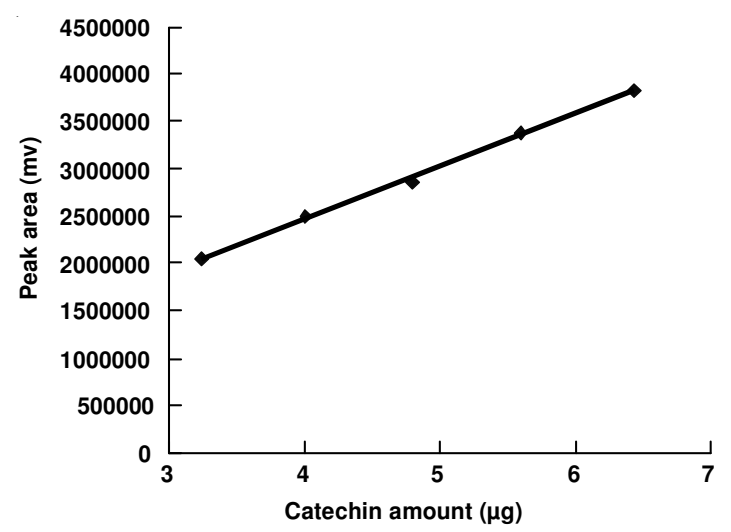

Fig. 1. Standard curve of catechin by HPLC

Result of precision test: The RSD of reference catechin peak areas was $1.28 \%(n=5)$, which suggested the instrument was of good precision.

Result of stability test: As shown in Table-1, the result indicated RSD of catechin peak areas in control solution was $1.166 \%(\mathrm{n}=5)$, which suggested the catechin samples were stable in $4 \mathrm{~h}$.

TABLE-1

STABILITY TEST DATA OF CATECHIN BY HPLC

\begin{tabular}{ccc}
\hline Test time $(\mathrm{h})$ & Content of catechin $(\mu \mathrm{g})$ & RSD $(\%)$ \\
\hline 0 & 5.144 & \\
1 & 5.141 & \\
2 & 5.135 & 1.166 \\
3 & 5.078 & \\
4 & 5.006 & \\
\hline
\end{tabular}

Result of recovery test: As shown in Table-2, the result indicated the average recovery rate of catechin in high, medium and low concentration groups were 101.79, 99.98 and $99.21 \%$ with the RSD of $1.29,1.08$ and $0.44 \%$. The average recovery rate of the catechin was $100.33 \%$ with RSD of $1.44 \%$. These results show that the recovery is good, impurities do not interfere with the content of catechin samples measured.

\begin{tabular}{|c|c|c|c|c|c|c|}
\hline \multicolumn{7}{|c|}{$\begin{array}{c}\text { TABLE-2 } \\
\text { RECOVERY TEST DATA OF CATECHIN BY HPLC }\end{array}$} \\
\hline $\begin{array}{l}\text { Test } \\
\text { No. }\end{array}$ & $\begin{array}{l}\text { Addition amount of } \\
\text { tested substance }(\mathrm{mg})\end{array}$ & $\begin{array}{l}\text { Addition amount of } \\
\text { reference substance }(\mathrm{mg})\end{array}$ & $\begin{array}{l}\text { Actual measurement } \\
\text { value (mg) }\end{array}$ & $\begin{array}{c}\text { Recoveries } \\
(\%)\end{array}$ & $\begin{array}{c}\text { Average } \\
\text { recoveries }(\%)\end{array}$ & $\operatorname{RSD}(\%)$ \\
\hline 1 & 2.1 & 1.6 & 3.694 & 99.63 & & \\
\hline 2 & 2.1 & 1.6 & 3.680 & 98.75 & 99.21 & 0.44 \\
\hline 3 & 2.1 & 1.6 & 3.688 & 99.25 & & \\
\hline 4 & 2.1 & 2.0 & 4.098 & 99.90 & & \\
\hline 5 & 2.1 & 2.0 & 4.122 & 101.10 & 99.98 & 1.08 \\
\hline 6 & 2.1 & 2.0 & 4.079 & 98.95 & & \\
\hline 7 & 2.1 & 2.4 & 4.578 & 103.25 & & \\
\hline 8 & 2.1 & 2.4 & 4.517 & 100.71 & 101.79 & 1.29 \\
\hline 9 & 2.1 & 2.4 & 4.534 & 101.42 & & \\
\hline
\end{tabular}




\section{Study on analysis catechin by ultraviolet spectrophotometer}

Methanol method: $0.100 \mathrm{~g}$ catechin reference substance with constant weight is weighed precisely and put into 100 $\mathrm{mL}$ volumetric flask, then dissolved in a reference solution methanol: water $=15: 85$ and diluted to $100 \mathrm{~mL}$. Shake well, put it aside. Exact amount taken from the solution 1, 2, 3, 4, 5, $6,8,10 \mathrm{~mL}$ placed in $25 \mathrm{~mL}$ volumetric flasks respectively and diluted to $25 \mathrm{~mL}$ with reference solution. By wavelength scanning of catechin solution, determine catechin positions of absorption peak is $278 \mathrm{~nm}$ and make a standard curve at the peak position. As shown in Fig. 2, the result indicated the concentration of catechin had good linear relationship with absorbance in the range of $0.04-0.16 \mathrm{mg} / \mathrm{mL}$, the regression equation is $y=18.035 x+0.041, R^{2}=0.9993$. When the concentrations of catechin are in range of $0.20-0.40 \mathrm{mg} / \mathrm{mL}$, the linear correlation becomes bad.

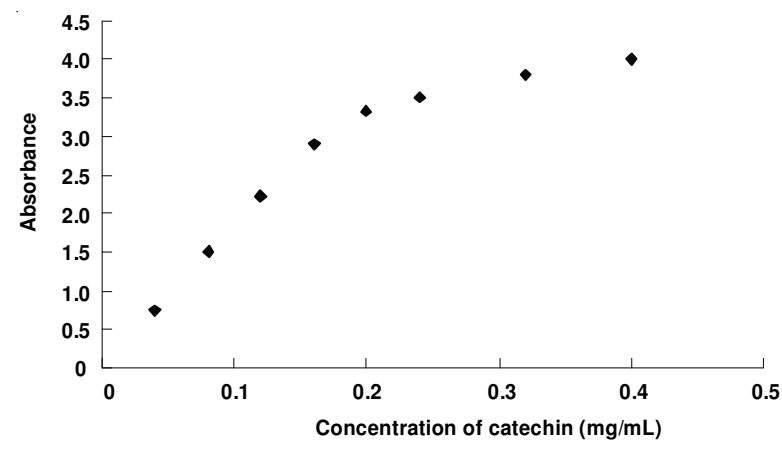

Fig. 2. Standard curve of catechin in methanol solution

Ethanol method: $0.100 \mathrm{~g}$ catechin reference substance with constant weight is weighed precisely and put into 100 $\mathrm{mL}$ volumetric flask, then dissolved in a reference solution ethanol and diluted to $100 \mathrm{~mL}$. Shake well, put it aside. Exact amount taken from the solution 1.25, 2.50, 3.75, 5.00, 5.0, $6.25,7.50,8.75$ and $10.0 \mathrm{~mL}$ placed in $25 \mathrm{~mL}$ volumetric flasks respectively and diluted to $25 \mathrm{~mL}$ with reference solution. Fig. 3 showed that the concentration of catechin had good linear relationship with absorbance in the range of $0.05-0.40 \mathrm{mg} /$ $\mathrm{mL}$, the regression equation is $\mathrm{y}=0.05 \mathrm{x}, \mathrm{R}^{2}=1$.

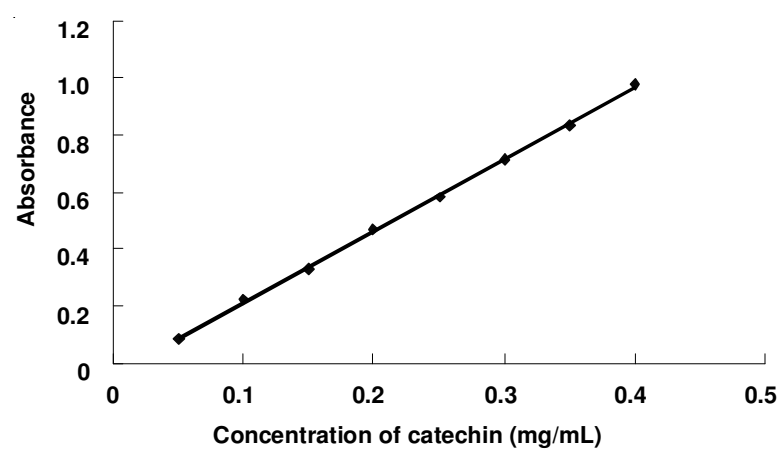

Fig. 3. Standard curve of catechin in ethanol solution

Phosphorus molybdate method: Reference solution, add $10 \mathrm{~mL}$ water, join $0.005 \mathrm{M}$ phosphorus molybdate $7 \mathrm{~mL}$, then add $6 \%$ sodium carbonate solution $5 \mathrm{~mL}$ diluted with water to the mark of $25 \mathrm{~mL}$ volumetric flask, shake well. A small amount of catechin reference substance with constant weight is weighed precisely.
$0.100 \mathrm{~g}$ catechin reference substance with constant weight is weighed precisely and put into $100 \mathrm{~mL}$ volumetric flask, then dissolved in water and diluted to $100 \mathrm{~mL}$. Shake well, put it aside. Exact amount taken from the solution 1.25, 2.50, $3.75,5.00,5.0$ and $6.25 \mathrm{~mL}$ placed in $25 \mathrm{~mL}$ volumetric flasks respectively and diluted to $25 \mathrm{~mL}$ with reference solution. Fig. 4 showed that the concentration of catechin had bad linear relationship with absorbance in the range of $0.05-0.30 \mathrm{mg} / \mathrm{mL}$. The regression equation is $\mathrm{y}=6.232 \mathrm{x}+0.7384, \mathrm{R}^{2}=0.9991$.

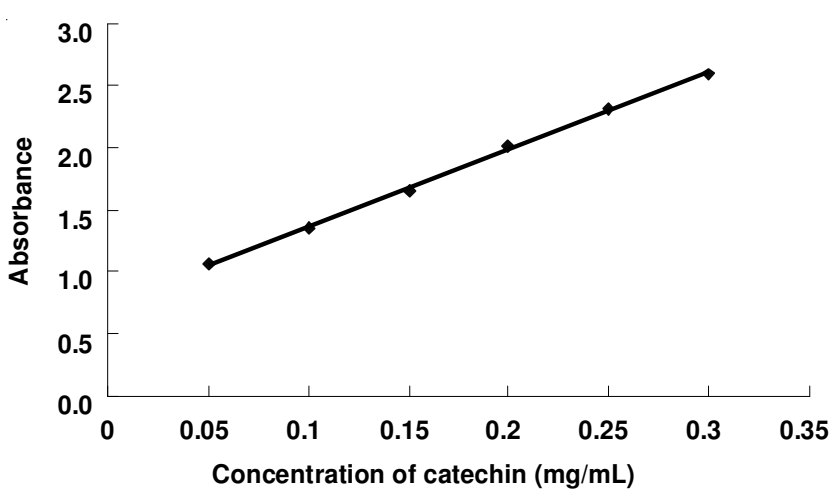

Fig. 4. Standard curve of catechin in phosphorus molybdate solution

A comparison of Figs. 2-4 reveal that the linear range of ethanol is relatively wide and the concentration of catechin had good linear relationship with absorbance, the preparation of the test sample is also relatively simple. So ethanol is used as a constant volume solvent in UV.

\section{Conclusion}

This experiment studied catechin determination. The contents of catechin was determined by HPLC and UV. Methodology investigation indicated HPLC standard curve: $y$ $=555111 \mathrm{x}+248469, \mathrm{R}^{2}=0.9982$, the linear relationship between catechin concentration and peak area was good in the range of 3.24-6.43 $\mu \mathrm{g}$, the catechin samples were stable in $4 \mathrm{~h}$, the recovery rates of the catechin was $100.33 \%$ with RSD of $1.44 \%$. In UV analysis, ethanol was as a constant volume solvent, the absorbance of catechin was measured at $278 \mathrm{~nm}$. Determination of catechin standard curve was $\mathrm{y}=$ $0.05 \mathrm{x}, \mathrm{R}^{2}=1$, linear range was $0.05-0.4 \mathrm{mg} / \mathrm{mL}$.

\section{ACKNOWLEDGEMENTS}

This work was supported by Biochemical Engineering College of Beijing Union University Subject Construction Projects.

\section{REFERENCES}

1. X.C. Wan, Tea Biochemistry; Beijing; China Agriculture Press (2003).

2. S.A. Kumar, M. Suresh, S.N.K. Kumar and P. Kalaiselvi, Asian J. Chem., 23, 4603 (2011).

3. B. Srividhya, V. Raj and R. Subramanian, Asian J. Chem., 23, 4603 (2011).

4. M. Golebiowski, E. Malin'ski, M. Szankin, M. Marszeniuk, M. Paszkiewicz and P. Stepnowski, Chem. Pap., 64, 729 (2010).

5. R.O. Urek, H.A. Kayali and L. Tarhan, Asian J. Chem., 20, 3750 (2008).

6. D.M. Goldberg, A. Karumanchiri, E. Tsang and G.J. Soleas, Am. J. Enol. Viticult., 49, 23 (1998).

7. M. Kofink, M. Papagiannopoulos and R. Galensa, J. Agric. Food Chem., 12, 1274 (2007). 